\title{
“The Meaning of Life" during a Transition from Modernity to Transhumanism and Posthumanity
}

\author{
Sirkku K. Hellsten \\ Department of Political and Economic Studies, University of Helsinki, Unioninkatu 40 A, P.O. Box 24, 00014 Helsinki, Finland \\ Correspondence should be addressed to Sirkku K. Hellsten, sirkku.hellsten@helsinki.fi
}

Received 30 September 2011; Accepted 1 January 2012

Academic Editor: Scott M. Fitzpatrick

Copyright () 2012 Sirkku K. Hellsten. This is an open access article distributed under the Creative Commons Attribution License, which permits unrestricted use, distribution, and reproduction in any medium, provided the original work is properly cited.

The articles argues that due to the rapid development of new technology the boundaries of life and death, as well as the different phases of our physical, social and spiritual life are getting less clear-cut and evident than they have been before in the Western, traditionally dualistic cultural and historical experience. Thus, at the moment we are in a transitional stage in our understanding of "human life" is gaining new dimensions in form of "post-humanism" and "trans-humanism". The current neo-holistic view of the universe and the human place in it requires us to consider the "existential risks" and seriously ponder the effects of the technological evolution to our social, cultural, ethical and metaphysical frameworks and normative principles.

\section{Introduction}

This special issue of the Journal of Anthropology focuses on the anthropology of transition in relation to birth and death at the beginning of the 21st Century. Birth and death are usually seen transitional periods in relation to human life presenting arrival and departure from/in life. In This article, however, claim that the Western-and particularly the Northern American - approach to birth, death, and life in general is now itself in a transitional stage.

I will argue that gradually the boundaries of life and death, as well as the different phases of our physical, social, and spiritual life are getting less clear-cut and evident than they have been before in the Western, traditionally dualistic cultural experience. Two, sometimes apparently contradictory, trends are emerging: on the one hand, while our individual, personal choices are further multiplying, and the individual human beings can live longer than ever before while remaining physically and mentally "younger," the overall human existence is becoming more "uniformed" as we appear to make choices towards "the same ideal of human life." On the other hand, the large-scale risks to human life are now maybe more evident than before. Climate change and other man-made or natural disasters can trigger large-scale and long-term catastrophes with destruction that is beyond human control. The use of new powerful but vulnerable technologies, such as nuclear power/war technologies, bio-, gene-, or nanotechnology can bring changes our living environment (that affect individual as well as the species of human beings) that could fundamentally alter the basic characteristics of human life. Global, free market economy based on self-interested profit maximization is ready to sell information, knowledge, and technology to those who are ready to pay the most whatever their motives may be. At the same time, the same global markets have proven to be very unreliable and prone to financial crisis that affects all parts of the world. New aggressive diseases and highly contagious epidemics occur despite all the recent advances in medicine. Global media and in general the fast new communication technology keep us informed about disasters, violence, and suffering across the world. However, at the same time we have become more and more aware how vulnerable and helpless we are, as individuals and as human beings collectively, in front of the nature-as well as in front of our own technology.

Ironically, the same technologies that humans originally invented and built in order to control the nature and our environment can now either deliberately or inadvertently be 
used to destroy a massive number of humans at once, if not "the whole human kind" in the end. There are researchers who claim that some of the greatest risks to humanity as a whole are actually a consequence of the radically transforming technologies, particularly such as nanotechnology systems and machine intelligence. These same voices are cautioning that the human kind needs to start preparing for a transition to "post-human" society. ${ }^{1}$ (See on post-humanism, for example, [1-3]). Others see this merely as a part of evolution, as a trans-humanistic stage leading to a wholly new and different forms of existence and the use of reason $[2]$.

In summary, while we have more "consumerist" choices in our individual lives, we appear to have less control on our lives or the future of the human beings in the long term. Our gradual, wider realization of the interdependency of human beings, technology, nature, and the universe as a whole is leading towards a form of neoholism that is gradually replacing the mechanistic and atomistic worldview that has been typical to the Western culture, particularly since the Enlightenment. Simultaneously, and somewhat ironically, the culture traditionally promoting individual choices produces collective decisions as people tend to "independently" choose the same trends, fashions, products, commodities, and so forth that takes them closer to the "human ideal" that we have defined for ourselves and enforced by our philosophical, ethical and social frameworks. This emerging neoholism not only transcends the modern dualism and the fragmentation of the Western worldview during postmodernism but it also creates new challenges to our traditional ethical reasoning by producing a whole new understanding of the relationship between humanity and ethics as it questions our traditional understanding of "birth" and "death," and the very concept of "life" in a wider sense. ${ }^{2}$

\section{2. “Technoscience”, “Cyber Culture," and the Changing Ethics towards Human Life and Death}

Human life is usually seen to have an intrinsic value, at least by us humans. Birth and death, for their part, are seen the liminal periods during which individual human beings are entering and exiting life and our "human culture." In order for us to make sense of the limits of human life and to give some meaning for our (individual and species) existence, human beings have created religions and other spiritual understandings of "after-life" with promises of continuity of our individuality beyond our biological existence. To bring fundamental value and meaning to our lives, we rely on concepts such as "human soul" or "re-incarnation." In order to socially deal with the transitional stages of human life throughout time, different cultures have created various rituals, rites of passage, traditions, practices, and general ethical frameworks that are based on different formulations of the concepts of "human dignity," "human value," or "human worth."

Throughout the history, humans have always also strived for eternal life and there have been quests for the Fountain of Youth, Elixir of Life, and other efforts to stave off aging and death. The elated contemporary philosophical ideologies of trans-humanism that focus on the human control in enhancement of human capabilities, radical life extensions, physical immortality, and even resurrection with the help of scientific methods are rooted already in Renaissance humanism and the Enlightenment. However, what was earlier only predicted and dreamt of, has now, for a large part, become a reality. (See, e.g., [4, 5] pages $11-17,31-$ $42,50-70,[3,6,7]$.) The rapid scientific and technological development of the last century has gradually challenged our traditional understanding of the "goalposts" in human life. The opportunities and threats which are brought by the new scientific knowledge and its technological application challenged us to reconsider some philosophical questions: when does (human) life really begin (e.g., in relation to the conception and to the termination of pregnancy)? Similarly the end of life questions have made it even more difficult to decide when is it right (time) to (choose to) die? When technology can keep us biologically alive even when our "consciousness" and, in general, our mental capacities that are often used as a criteria to define humanity (such as self-awareness, rationality, autonomous decision-making) no longer exist, we are left with the ethical questions related to the "accurate" quality for human life: what kind of life is worth of living-what kind of life is human enough for human beings? How long/until when is it ethically agreeable to live in a world of scarce resources. This last question relates to the issues of fair distribution: while human life is of the ultimate value, as (individual) human beings can live longer and older, how can we deal with the fairness of the distribution of the scarce resources-not only globally speaking but also between the generations? Does the right to life_-and to a life of certain minimum quality-concern those yet unborn? What makes human life human and when-if ever-can an individual human being lose human value: is what is called human value or human dignity a question of genetics, individuality, reason, senses, selfinterest, consciousness, or personhood. ${ }^{3}$

Humans have always had a desire to believe in a supernatural being that is in control of the universe, our world, and even up to a degree of our individual lives. Many people get comfort in thinking that the same supernatural power/ powers can provide us with sets of moral values and ethical guidelines. However, Friedrich Nietzsche (1844-1900) noted already in his The Gay Science (1882) and Thus Spoke Zarathustra (1885) that in relation to the scientific explanation of the world "God is dead." Today the postmodern ethos have further declared that there are no "great stories" that can provide us an overarching explanation on the meaning of human existence or give us universal moral principles. Instead we are left on our own to find ethical guidelines to be applied in culturally, politically, and economically different environments. In this sense, religion has been a question of faith, while science has been a question of knowledge-both of them fulfilling the different spheres of human curiosity and the need to understand the human place in the universe. Particularly after the Enlightenment, the spheres of religion and sciences have been quite separated, unlike during, for 
example, the Ancient (or so-called "traditional") thinking that can comfortably integrate the philosophical questions on the "meaning of life" with scientific research, and spiritual beliefs. All in all, thinking that brings all human experiences together. (See also $[8,9]$ ).

However, particularly recently and in the context of postmodernism, the proponents of new science, new technology, and "cyber culture" have brought together the spiritual understanding of the world with the scientific "revelations" guiding our worldview towards neoholism. For the issues of morality and for our spiritual enhancement, particularly the New Age movement has brought together science, technology, and traditional and futurist visions. It has different trends from UFO faith to neopaganism, modern witch craft, and channeling. ${ }^{4}$ Despite the fact that this world view may appear chaotically fragmented, it nevertheless shows transitional trends towards neoholism that is gradually moving away from the dualistic world view. Instead, it brought together rational, emotional, material, and spiritual aspects of the universe. UFObelievers can intertwine the stories from the Bible and the Qur'an to views that are presented in the postmodern science fiction. Jesus and Mohammed may be seen as visitors from another planet that has already passed to a more advance stage of thinking or post-humanity that entails intelligence and powers that we can presently only imagine. (For more on New Age combination of scientific and spiritual aspects of human life and human abilities, see, for example, [8-12]. $)^{5}$

In general, while science is thought to produce "objective facts" that describe and explain our world, we need to find a way how to deal with these "new facts" we learn about the universe and about ourselves. However, the technological applications of science are now developing so fast that our traditional moral outlooks and social structures are left in dumbfound and our ethical frameworks are dragging behind. At the same time, the laws of globalized market economy and consumer culture encourage people to focus on "I" and "here and now" rather than on the cause and effect chains that would make people consider more profoundly the wider radical ethical and social consequences of our present actions and inventions.

The choices in life that individual humans can now make have been escalating particularly when it comes to the issues of birth, life, and death, whether we speak of our own lives or those of our offspring. Without any overarching, consistent ethical framework, the criteria for these choices have become random and clearly more consumerist. As Michel Foucault observed, the neoliberal agenda and its biopolitics ${ }^{6}$ have created a pseudo-individualistic culture that is based on capitalist consumerism and presents only superficial choices but really not a free will. The market mechanisms that lead the neoliberal political agenda in the end create a more unified society in the name of "scientific knowledge," "normality," "good health," and "self-responsibility" ([13] pages 73-79, 91-101, 303-315, [14]). In a social context, an individual choice becomes then illusionary as our collectivist ideals of human life are more and more identical and enforced by biosciences and technology, as well as by fashion and market trends.

\section{Birth and Death as Consumer Choices}

Let us take a simple example of consumerist approach to a beginning of life from the reproductive choices we have today. Contraception, termination of pregnancy, as well as infertility treatments are more or less routine in most of parts of the Western world. Conservative and religious groups may still raise objections, but these practices are in general accepted both medically and socially. At the same time, they are often seen as an essential element of moral autonomy of the rational individuals as "moral agents." They also are seen as significant rights of women to have more control over their bodies and lives in general. In fact, they have created a whole new uncharted territory of personal choices to women and to whole families. The recent new ethical issues have been raised for example in relation to "selective abortion." While abortion is currently somewhat accepted and particularly when an unborn child may be expected to have serious genetic, physical, or mental disabilities (abnormalities), more moral discontent arises in relation to multiple pregnancies and woman's choices to reduce her pregnancy to one. Multiple pregnancies are often results of infertility treatments that, for their part, give more women, and also at older age, a chance to bring their own biological children into being. However, they also often produce more than one fetus. Women who end up with multiple pregnancy may choose to reduce the pregnancy to a singleton even if all the fetuses are perfectly healthy. While the choice might give this one fetus better chance of survival than two or more would have had, it is often also related to the woman's other choices in life: her stage of career, personal relationship, and other social and economic conditions. The following quotation from a woman interviewed for New York Times on the artificial reproductive technologies (ARTs) describes well the changing attitudes towards pregnancy and birth: "...but we created this child in such an artificial mannerin a test tube, choosing an egg donor, having the embryo placed in me-so somehow, making a decision about how many (fetuses) to carry seemed to be just another choice. The pregnancy was all so consumerist to begin with, and this (i.e., reducing the pregnancy to singleton) became yet another thing we could control" [7].

The technologically and economically advanced Western countries no longer see birth "as a miracle of life," but instead we want a perfect number of perfect children that fit "perfectly" in our life plans. With genetic technology, we can already avoid some unwanted disabilities and genetic abnormalities, but soon we will be able also to enhance our off-spring to be intellectually and physically utmost advantaged. We soon easily aim towards the "ideal rational decision maker" that has since the Enlightenment been the hypothetical ideal of the subject of liberal individualism. Again, Foucauldian analysis of neoliberal biopolitics seems to hit home: the closer we get to producing "the ideal individual," the more uniformed our societies will come and less room 
there is for the traditional humanistic tolerance for difference and diversity ([13] pages 73-79, 303-315, [14]). Again individual choices produce collectivist selections that are guided by "the invisible hands of the markets."

The changing attitudes towards transitions in life can also be seen in uniformity of life. It is not only the exact borders of the beginning or the end of life, birth and death, that have been questioned. Also the various passages or stages of life are gradually becoming more blurred when individuals are perfecting themselves: medicine and technology, as well as the trends of fashion and social pressures in a globalized economy and cosmopolitan culture encourage individuals across the world to strive for the same norms and ideals. Consequently, the younger want to appear more mature, the mature want to look ageless, while the elderly want to engage in the same activities as their grandchildren. The darker ones want to lighten their skin while the fair ones want to get a tan. With all forms of cosmetics and medical and scientific procedures, we are gradually creating the society of almost identical "clones" with or without actual genetic cloning which is also already available up to a degree. The rites we have used to move from one passage of life to the next one have become meaningless and outdated as we no longer recognize or adapt to the transitional stages or passages in our "ageless" lives. (See also [13], pages 73-79. ${ }^{7}$

Similarly our choices have increased at the end of our lives. We can-or at least those with sufficient economic means - not only buy years to our lives but also delay our aging through various medical and technological means provided by medical treatments such as genetic therapy, plastic surgery, hormone treatments, and antiaging cosmetic procedures and various other methods. Not only it is a possibility, but in a sense it is becoming our responsibility to take as good care of ourselves as we can with all means available. And once we fail in remaining in an ideal condition, it is time to go (i.e., to leave a biological life as we understand it now), and we should prepare for that also. In the USA, for example, funeral homes are advertising their services as "final gifts" to our children. Similarly do the agents of life insurances. When we leave this earth, we should make sure we are not creating any burden to those we leave behind. ${ }^{8}$

\section{Ethics of the "New Age" of Transhumanism}

The traditional Western, individualist approach to ethics has its foundations in the concept of a rational agency and personhood (other characteristics such as consciousness, selfawareness, sententiousness fall under this same category). As noted earlier the ethical questions we have presented in dealing with the issues of life and death in relation to the new technologies (bio-, gene, nano-, and information technology) have focused around such questions as "when does life begin and when does it end" (in relation to an individual human being) or "what is the value of human life: what are the/minimum standards for a good life."

This is essential as our biological life and its quality has been our main concern. There has already been attempts to create life artificially and debates around "the concept of life"-what really qualifies as "life"? The ethical debates on the standards of quality of "human life" are now already extended to more metaphysical questions on what qualifies as "human life". Until now a human being's intelligence is intimately tied to his or her physical body, and our choices have been limited in taking care of this physical body the best way we can. As the human brain is very finite, we have not been able to physically extend or copy it. However, within the studies of artificial intelligence and advance computer science, the predictions are that in not so distant future we will be able to also move human "mind" on a computer disc. (See [5], pages 10-31, [3, 6]). Our physiological and biological limitations would then not prevent the extension of our (individual) existence. At the same time our "human form of existence" would radically change from a physical, biological being to a nonphysical being living in a virtual reality setup by a digital information system of a super intelligent computer. All new categories of ethical dilemmas would emerge: who is in charge of the computers and their maintenance, whose minds are copied and based on what criteria? If all human minds could or would move into virtual reality and continue "living" in cyber space then who or what is left behind to maintain the operations. If this "caretaker" is artificial intelligence that greatly supersedes human intelligence, what interest would it have to preserve intellectually inferior human minds, except maybe as "curiosities of the past," "pets" or "test cases," or "historical archives." The most important question is, of course, what would be left of humanity in the first place. (On the discussion on human minds in computers as well as super intelligence, see in detail $[3,6,15,16]$.)

These possibilities that result from the various combinations of new information technology, medical technology, genetic research, molecular nanotechnology, and quantum physics are fundamentally changing the human understanding of "time and space," as well as the physical/material and immaterial forms of existence have been mapped out, for example, in Kaku [5], Kurzweil [3], Silver [17], and Zeleski [18]. In general we can note that today science is already providing explanations that support the holistic view of the universe thus challenging the traditional Western ethical thinking has been based on metaphysical dualism rooted in and promoted by the big world religions, such as Christianity and Islam. Even those who do not hold fundamental religious beliefs about the meaning of life still tend to separate mind from body, life, and after- or pre-life forms of existence, and in a Platonic sense the form from the matter. With the emergence of neoholism, our current ethical thinking that is still at least partly based on the physical, biological existence of individual humans as moral agents whose choices are affected by our will for self-preservation, our general fear and distaste for physical and emotional pain and to the limits of our life span, that is, our mortality, is gradually challenged to consider alternative metaphysical frameworks. This forces us to think ethical dilemmas and solutions in a whole new way. (For more discussions on the threats and possibilities of the integration of new sciences and technology, see $[1,3,6,15,17-20]$; on integrating the views of new physics and eastern philosophy, see, e.g., $[8,9]$.) 


\section{The End of Mortality or the Beginning of Posthumanity?}

Once the neoholistic world view gains more ground, we may also have to give up on our ideal of human individuality and uniqueness as a fundamental feature of humanity. Earlier we mentioned that the social context of individualism adds our choices superficially while enforcing collectivist outcomes and end states. As a consequence of new scientific revelations and related technologies, the concept of individualism is challenged also at the metaphysical level, when the holistic nature of universe is confirmed, the distinction between mind and matter abolished and the collectivist foundation of universal conscience further explained. Some scientists have already presented theories that our consciousness or what has been called "soul" might not be anything else but a well-developed information system that possibly continues its existence outside our biological body after our physics have stopped functioning and we have reached our biological death. Maybe not individually and independently but rather integrated into a holistic, universal system of intelligence that brings the information mechanisms of all nature and universe together. This could provide room also for the Eastern believes of reincarnation and "recycling of souls." In other words, the Western science is now taking us towards the oriental and ancient philosophies that have introduced the idea of reincarnation. (See for example [8].)

Others working on computer science and artificial intelligence such as Hans Moravic [6, 15, 21], Ray Kurzweil [3], and mathematician and author Vernor Vinge [22]just to mention few-radically predict technological change already within the next few decades. When computer science is combined with quantum physics and nanotechnology, the result may soon be a combination of a human being and machine, or as Ray Kurzweil and Vernor Vinge have put it "Singularity." The concept refers to intelligence explosion and technological creation of superintelligence that will bring about total change in our human society. Next to this revolution, the ongoing physical, political revolutions are nothing, as our whole concept of humanity has to be reconsidered and we might make a machine that is more intelligent than us. The singularity will represent the culmination of the merger of our biological thinking and existence with a technology, resulting in a world that is still human but that transcends our biological roots ([3], pages 10-31).

While some ethical dilemmas might be obvious for us, already now their formulation is still based on dualism, at least up to a degree. For example, if "individual human minds" are downloaded on a computer disc, indeed it would appear that we could solve some burning ethical issues, such as overpopulation and limited resources combined with the principles of just distribution. At the same time, we can think of new dilemmas, such as who would be in charge of these supercomputers our minds would be living in; what if there is an energy failure and a whole continent of "souls" disappear from being. Or would these questions by then be outdated as we have by then evolved from our traditional form of human existence to whole new metaphysical and ethical dimension-or maybe to a form of being where “ethics," "religion," and "science" no longer matter at all. In this new form of existence, we would no longer have to worry about life and death as such, not to be concerned of physical pain, aging, and disease (except maybe computer virus); we would no longer would feel fear, attachment, emotions of failure, and success neither could we experience love, hate, and other emotions related not only to the meeting of minds but also to that of bodies, to our whole psycho-sociophysical existence. Ironically, we would then in a sense to be closer to the Platonic ideal forms but much further away from ethics and morality that only belong to the reality of the imperfect copies made our of matter.

The futurists do not see singularity as an impossible scenario, but rather as an inevitable evolutionary stage. Kurzweil [3] notes that the change to "singularity" would be unintelligible to us afterwards in the same way that our present civilization is unintelligible to a goldfish. Thinking about the possibility of creating or becoming something of superhuman intelligence is an example of an optimism that is so far reaching that it should force the human beings to look carefully at what it is really that we have wanted. In other words, we as humans have been striving to make our lives better for a very long time, but now we might be entering an era where questions like "what is the meaning of life?" will be practical engineering questions rather than philosophical and ethical questions asking of which we have thought to be the very basis of what we presently call "humanity." (See $[3,6,9,22]$.) In that stage of evolution of "life," there might not be anyone or anything asking philosophical and ethical questions on "what is the value of human life" or "what is/ was humanity-leave alone humanism - in the first place."

In relation to the above, intellectual and cultural movements of posthumanity and its subset of transhumanism (often abbreviated as $\mathrm{H}+$ or $\mathrm{h}+$ ) have affirmed the possibility and desirability of fundamentally transforming the human condition by developing and making widely available technologies to eliminate aging and to greatly enhance human intellectual, physical, and psychological capacities gaining more popularity. Some proponents of posthumanity are optimistic and see that the turn can only be towards better. Others are cautioning us to prepare to leave everything we know now behind and to be really live in a world that our current level of human intelligence might be comparable to that of a chicken or maybe an ameba from our present point of view.

If we think about the antiaging technologies and those that are aiming for immortality or at least almost endless life, we might meet gloomy future. Let us use cryopreservation as our example. Cryonics companies believe that what they call suspended animation will be perfected eventually and that it will be possible to routinely turn people "off" and "on" for medical time travel, space travel, and other purposes. They claim that, as progress continues, it will become possible to recover people preserved at earlier times, as the medicine attains full control of human body at the molecular level. As the cryonics promises, you only need to be "legally death" and you can be preserved to be revived when the technology is there. ${ }^{9}$ 
However, if the development of artificial intelligence is as speedy and "singularity" takes place in a near future as some scientists and futurologists predict (see for example $[3,5])$, my potential investment with cryopreservation may have unintended consequences. Once I will be revived again to the form of human existence what we now consider as intrinsically valuable human life, I might wake up in a very different world that I have no way of understanding. If the potentially then ruling superintelligence has any interest to revive me at all, I might wake up in a world that I am the last of my species. For the superintelligence, I might have no value, except maybe for some experimentation or historical exhibition. I might end up living in the world in which ethics and morality — as we know them now-have no place. What we consider moral and ethical guidelines on how to treat individual human beings might be totally unintelligible or futile to the superintelligence or the collection of "computer minds."

\section{Conclusion}

It is evident that humanity is at cross roads in its approach to virtual reality, morality, spirituality, and ethics. While many of us still today understand the world and the universe through "dualistic glasses" that separate body and mind, our vision on this distinction is getting already more and more blurred. Virtual reality, cyber space and developed computers, and internet connections have already given us a chance to communicate across the globe without physical presence through virtual reality. Present medicine and technology can already manipulate our genetic inheritance, clone some biological organisms, and enhance our capacities where needed. Reproductive medicine and technology has given us the chance to choose when to give birth, artificially or naturally-while the line between the two concepts: life and death, is also getting hazier. In the end of life we have options not only to lengthen our physical lives but maybe even continue our existence in other forms presently unknown or hardly imaginable for us. In the combination that the modern science, technology, and market economy have brought together, our traditionally dualist world view is slowly further fragmented and eventually replaced by a more holistic one.

At the moment, as individual human beings and as members of the human kind, we are in a transitional stage in our views towards such fundamental transitions in human life as birth and death, and our wider conception of reality around us. The rapid development of technology may radically change the whole concept of life and related ethical views already by the end of ethics of 21st century. The idea that we will be able to live almost forever in our physical form, that human consciousness could be digitalized on hard discs of computers, or that we might be ruled by computers which are intellectually superior to us will not only change the understanding of life, death, and birth but it also changes the whole current and traditional moral and social human system-or rather leaves it irrelevant. Should we develop artificial intelligence that leaves us intellectually "challenged" and inferior, our "humanity" may become trivial to this superintelligence, and the contest of resources may lead to the distinction or extermination of the human kind. Therefore, it is important to consider seriously the "existential risks" and the related scenarios of future and ponder the wider consequences that what we today may see as science fiction-as indeed in the future "the transition in humanity" might be too fast for the humans to keep up with. Finally to return to the beginning of my paper, what we now consider as "birth" and "death" may no longer be relevant concepts either.

\section{Endnotes}

1. For the concept of existential risks, see Bostrom 2002.

2. Posthumanism or post-humanism has various definitions, but in general it refers to conditions "after or beyond humanism" - metaphysically, evolutionarily, intellectually, socially, ethically, and/or culturally. Transhumanism is a trend of posthumanism. It is an ideology and movement which seeks to develop and make available technologies that eliminate aging and greatly enhance human intellectual, physical, and psychological capacities, in order to achieve a "post human future." See for more details Bostrom 2005.

3. Bioethics has been dealing with the beginning and end of life questions for the past decades, but now the scientific possibilities have expanded the scope of these questions beyond our traditional medical ethics. The traditional concepts of life, health, age, and death have gradually been redefined, or at least their scope needs to be redefined. Gerontologist and biologist Aubrey de Gray, for example, sees aging as an illness that can be cured and that people have no longer any reason to grow old and fragile but they can live as long as they want. According to de Gray, aging can actually be cured like the plague was cured in the middle ages. See Gray 2007 and Padawer 2011. Those who prefer to live forever can already invest in cryonics to preserve their biological bodies (sometimes a mere head is enough) and wait to be revived when the needed technology is there. See, for example, http://www.alcor.org/.

4. Channeling is a New Age title for a practice of spiritualism. In this practice the persons involved in the channeling allow themselves to be taken over by entities which claim to be spirits of the dead, angels, deceased gurus or wise men, or even alien beings.

5. See also Grossman 2011, http://www.time.com/time/ magazine/article/0,9171,2048299,00.html.

6. In the work of Michel Foucault, biopolitics refers to the style of government that regulates populations through "biopower," that is, the application and impact of political power on all aspects of human life. In a wider context it is a political spectrum that reflects positions towards the sociopolitical consequences of the biotech revolution, one of which is that our choices become "pseudo-individualistic" as we all reach for a "collective ideal of perfect human being" Foucault 1994, 73-79. 
7. However, at the same time the poor in less developed countries are still dying young - and of hunger, malnutrition, thirst, and various easily curable diseases as well as of war and conflict.

8. The idea of significant changes to human longevity has been particularly controversial for our belief systems. People have invested a lot of personal effort into certain philosophies dealing with the issue of life and death. Our mortality is the major reason we have religion, as Kurzweil notes. Read more: http://www.time .com/time/magazine/article/0,9171,2048299,00.html\# ixzz1VhyUU7LH.

9. Alcor in Florida notes that what is fatal varies from place to place and time to time depending on available medical and so forth technology-it is true that future medical capabilities should be able to heal and cure in cases that today would be considered hopeless, as today's medicine would be viewed as miraculous in past centuries (http://www.alcor.org/FAQs/faq01.html).

\section{References}

[1] N. Bostrom, "Existential risks: analyzing human extinction scenarios and related hazards," Journal of Evolution and Technology, vol. 9, no. 1, 2002.

[2] N. Bostrom, "A history of transhumanist thought," Journal of Evolution and Technology, vol. 14, no. 1, 2005.

[3] R. Kurzweil, The Singularity is Near, Viking Press, 2005.

[4] A. De Gray, Ending Aging: The Rejuvenation Breakthroughs that Could Reverse Human Aging in Our Lifetime, St. Martin's Press, 2007.

[5] M. Kaku, Physics of the Future: How Science Will Shape Human Destiny and Our Daily Lives by the Year 2100, Doubleday, New York, NY, USA, 2011.

[6] H. Moravec, Robot: Mere Machine to Transcendent Mind, Oxford University Press, 1998.

[7] R. Padawer, The Two-Minus-One Pregnancy. New York Times, August 2011, http://www.nytimes.com/2011/08/14/magazine/ the-two-minus-one-pregnancy.html.

[8] F. Capra, The Tao of Physics, Shambhala, Boston, Mass, USA, 1991.

[9] M. Kaku, Visions. How the Science Will Revolutionize the 21st Century, Doubleday, New York, NY, USA, 1997.

[10] F. Crick, The Astonishing Hypothesis: The Scientific Search for the Soul, Scriber, New York, NY, USA, 1994.

[11] L. Grossman, 2045: The Year When Man Becomes Immortal, Times Magazine, 2011.

[12] T. MacKenna, Archaid Revival: Speculations on Psychodelic Mushrooms, the Amazon, Virtual reality, UFOs, Evolution, Shamanism, the Rebirth of Goddess and the End of History, Harper Collins, San Francisco, Calif, USA, 1992.

[13] M. Foucault, Ethics, Subjectivity and Truth. The Essential Works of Foucault 1954-1984, Edited by P. Robinow, The New Press, New York, NY, USA, 1994.

[14] M. Foucault, Power/Knowledge: Selected Interviews and Other Writings 1972-1977, Edited by C. Gordon, Harvester, Brighton, UK, 1980.

[15] H. Moravec, The Mind Children: The Future of Human and Robot Intelligence, Harvard University Press, Cambridge, UK, 1988.
[16] J. Broashurst Dixon and E. J. Cassidy, Eds., Virtual Futures, Cyberotics, Technology and Post-Human Pragmatism, Routledge, New York, NY, USA, 1998.

[17] L. Silver, Remaking Eden Avon Books, New York, NY, USA, 1997.

[18] J. Zeleski, The Soul of Cyberspace, Harper Edge, Harper Collins, San Francisco, Calif, USA, 1997.

[19] A. Berglas, Artificial intelligence will kill our Grandchildren (Singularity), 2009, http://berglas.org/Articles/AIKillGrand children/AIKillGrandchildren.html.

[20] N. Bostrom, Ethical Issues in Advance Artificial Intelligence, 2003, http://www.nickbostrom.com/ethics/ai.html.

[21] H. Moravec, Pigs in Cyberspace, 1992, http://www.primitivism.com/pigs.htm.

[22] V. Vinge, A Fire Upon the Deep, Toor Books, 1992. 


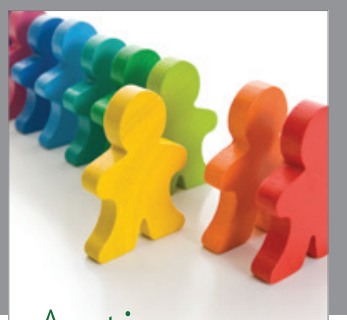

Autism

Research and Treatment
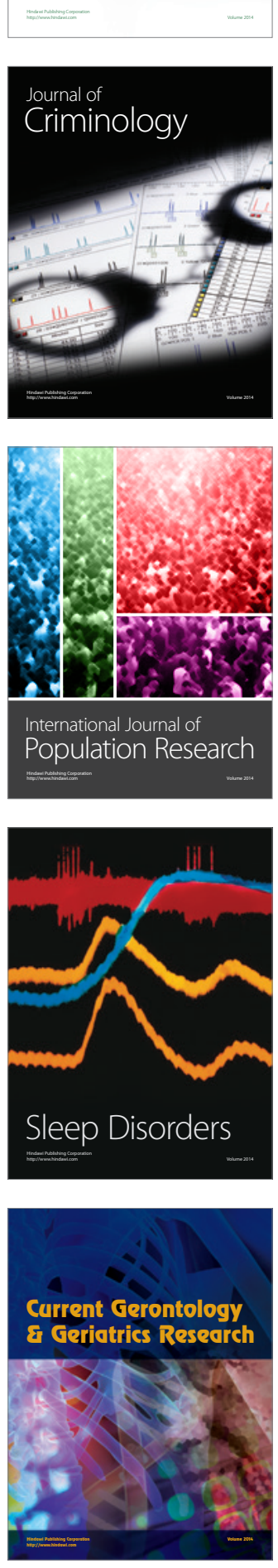
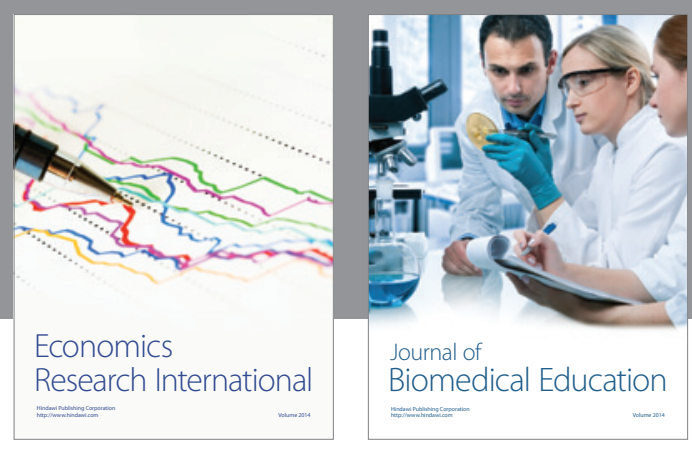

Journal of

Biomedical Education

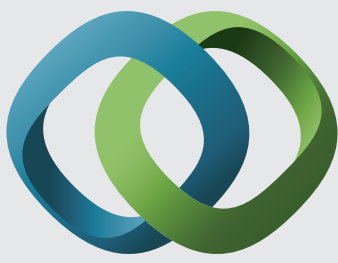

\section{Hindawi}

Submit your manuscripts at

http://www.hindawi.com
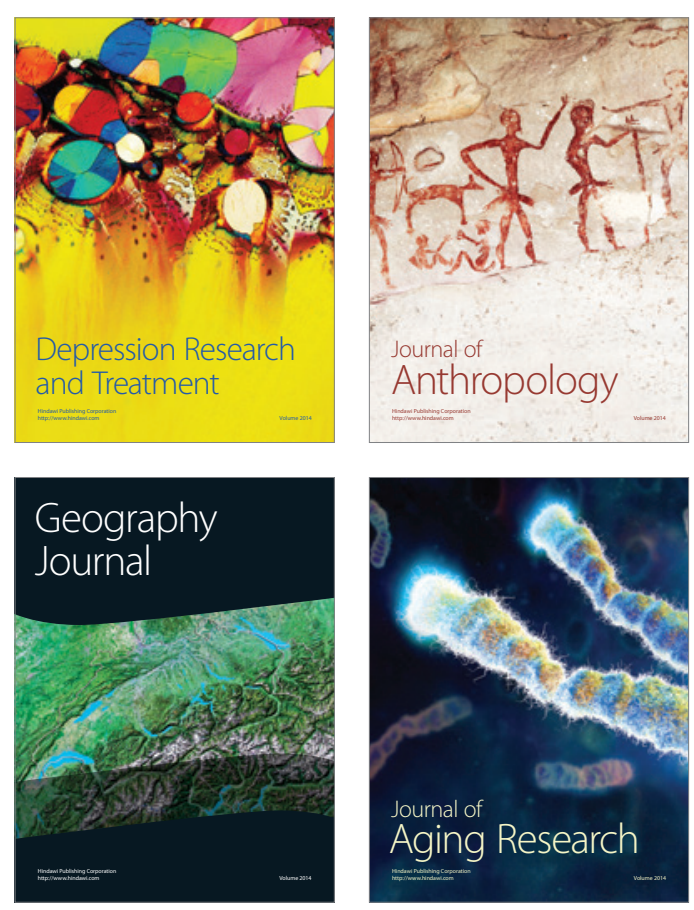

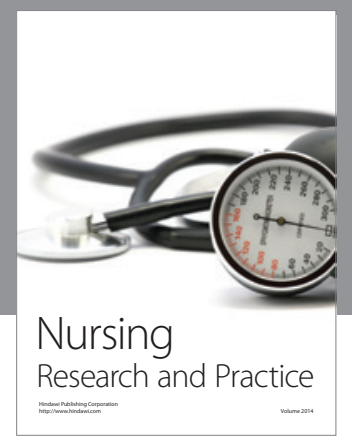

Nursing

Research and Practice

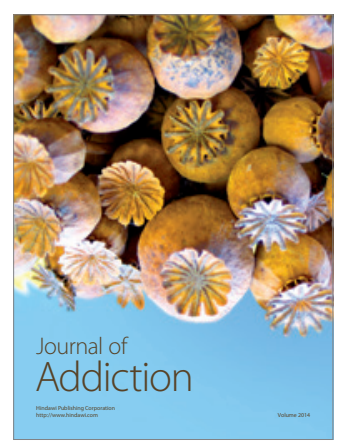

Child Development

Research

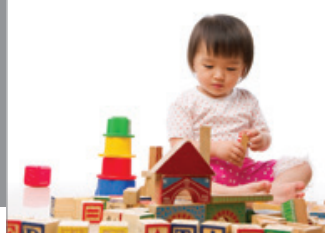

迥
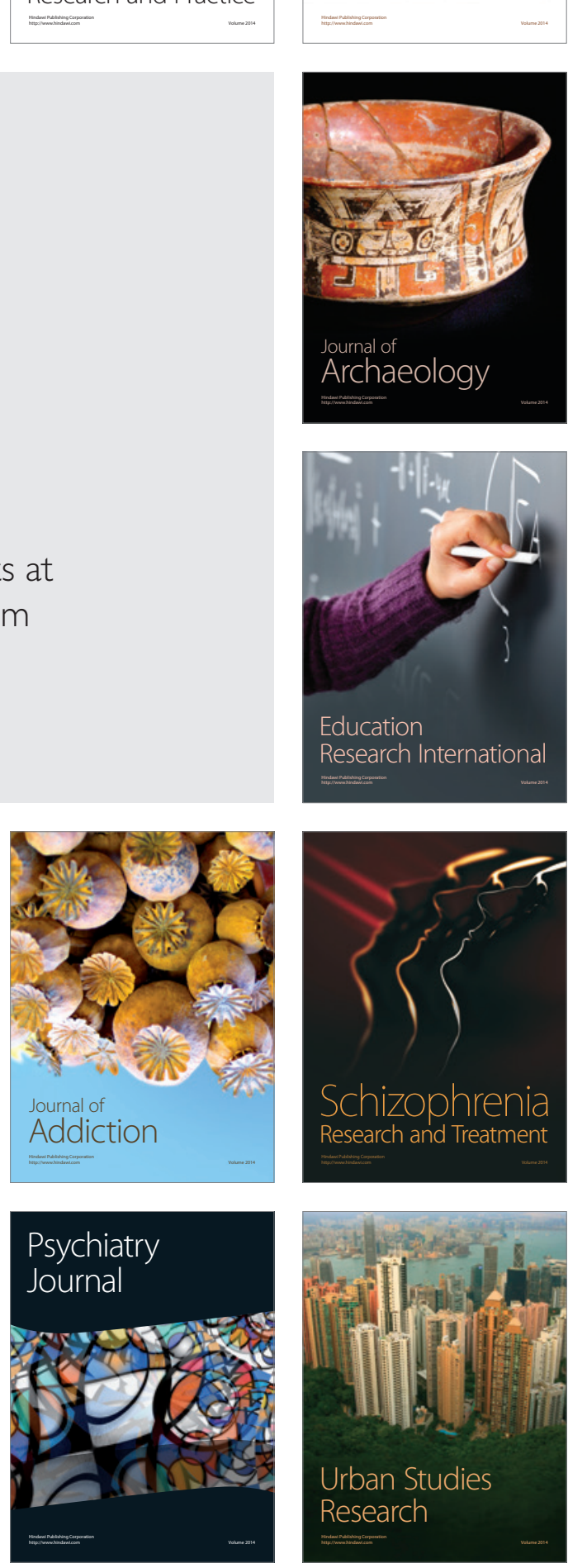